\title{
Nurse stress at two different organizational settings in Alexandria
}

\author{
Ashraf AZ Zaghloul \\ Nagwa Y Abou El Enein \\ Department of Health Administration \\ and Behavioural Sciences, High \\ Institute of Public Health, University \\ of Alexandria, Alexandria, Egypt
}

\begin{abstract}
Objective: The objective of the study was to explore the difference in stress levels among nurses working at two different health care organizations and the determinants of nurse stress within each organization. Job stress is defined as the harmful emotional and physical reactions resulting from the interactions between the worker and her/his work environment where the demands of the job exceed the worker's capabilities and resources.
\end{abstract}

Methodology: A convenient sample of nurses in two hospitals in Alexandria; Shark Al Madina $(n=120)$ and Karmouz $(n=170)$ hospitals. All nurses present at the time of the study were approached to be included in the study. The response rate for Shark Al Madina hospital was $94 \%$ and for Karmouz hospital, 71\%. Data collection took place using a nurse stress questionnaire previously developed and tested for validity and reliability to measure stress in clinical nursing practice. The $5 \%$ level of significance was used throughout the statistical analysis for all relevant tests.

Results: The highest mean stress scores were the same for both hospitals. The dimension of coping with new situations was $2.7 \pm 0.6$ at Shark Al Madina hospital and was $2.5 \pm 0.7$ at Karmouz hospital while the dimension of job security was $2.7 \pm 0.6$ and $2.5 \pm 0.7$ at Shark Al Madina and Karmouz hospitals, respectively. Stepwise multiple regression for Shark Al Madina hospital model revealed workload $(\beta=1.38)$, security $(\beta=5.04)$, and shortage of support staff $(\beta=3.39)$. For the Karmouz hospital model, stepwise multiple regression revealed security $(\beta=4.78)$ and shortage of resources $(\beta=3.66)$.

Conclusion: Stressors among nurses appear to be the same despite the differences in organizational or hierarchical structure where they work or the type of consumer they serve. It is important to reduce occupational stress in nurses and to strengthen their coping resources to prevent nurse burnout. This could be achieved with job redesign, modification of shift work systems, and by offering occupational health education as well as assurance regarding job security especially during the global financial crisis.

Keywords: nurse stress, stepwise multiple regression, stress, organizational structure

\section{Introduction}

Stress, particularly occupational stress, is of prime interest to employers in view of known adverse effects on personal performance, productivity, job satisfaction and health. Stress involves transactional relationships between individuals and their environment that are appraised as taxing or exceeding their resources and endangering their well-being. Stressors are objects and events; stress reactions are responses, both physiological (rapid heart rate, increased blood pressure) and psychological (anger, fear), that occur when confronted with a stressor. ${ }^{1}$ Nursing is generally perceived as a demanding profession. It is both physically and psychologically challenging. Over the past several years, signs of occupational stress appear to be increasing among nurses which has been referred to many factors ranging from downsizing, restructuring, and merging to role boundary and responsibility. ${ }^{2-4}$ Nurse stress is defined as the emotional and physical reactions resulting from the interactions between the nurse and her/his 
work environment where the demands of the job exceed capabilities and resources. ${ }^{2}$ All professionals can succumb to job stress and nurses are certainly not exceptions. Stress itself is not harmful. Too little stress can leave you listless and apathetic, whereas a small dose of stress can provide an edge and a positive boost of action. ${ }^{5}$ It is well known that prolonged stress is a precursor of burnout (characterized by exhaustion, increased mental distance from one's job, and reduced personal accomplishment) which is considered a major problem for many professions, and nurses are considered to be particularly susceptible. Within the same context, health administrators in institutions that deal with loss and bereavement need to be aware of the factors that can negatively influence the capability of the work force, especially nurses, to work effectively. ${ }^{6}$

A positive work environment is essential for the retention of nurses in acute care settings. In their review, Enrenstein and McCaffrey explored research by Sullivan and Decker (1997) that showed now the health care work environment is affected by health care consumers, health care providers, and economical conditions such as levels of reimbursement, technology, and regulations. ${ }^{7}$ Supportive literature by Kreitzer and colleagues ${ }^{8}$ characterize unhealthy work environments as those with high levels of stress, high nurse-patient ratios, overwhelming physical demands, communication problems between nursing staff and other health care providers, and verbal and physical abuse. These unhealthy environmental factors are present in varying degrees in the nursing work environment and precipitate nursing job stress. ${ }^{8} \mathrm{McCauley}^{9}$ asserts that there is continuing evidence that unsupportive and unhealthy environments contribute to medical errors and unsafe working conditions.

Health services in Alexandria are provided through various sectors: government, parastatal, and private. The government sector includes the Ministry of Health and Population (MOHP) facilities, the Ministry of Higher Education which supervises university hospitals, facilities, and teaching hospitals, as well as hospital organization, and the Ministries of Defense and Interior's health facilities. The parastatal sector includes Health Insurance Organization (HIO) and curative care organizations and other public sector organizations providing hospital services. The private sector provides services which include private clinics, private hospitals, private pharmacies, and nongovernmental hospitals.

None of the research conducted in Egypt had ever probed the concept of nurse stress, stress determinants, or whether stress determinants differ among the organizations rendering health care services. The aim of the study was to explore the differences in stress levels among nurses working at two different health care organizations and the determinants of nurse stress within each organization.

\section{Methodology}

\section{Study settings}

The study took place at two organizations which differed in regards to organizational hierarchy, type of services rendered, and type of consumer. These hospitals were the Shark Al Madina hospital and Karmouz hospital. The Shark Al Madina hospital ( 150 beds, 128 registered nurses) is affiliated to the MOHP and is considered a tertiary level health care facility. The Shark Al Madina hospital is the only center of excellence in Alexandria and is affiliated to the Minister's Office, a tertiary hospital that provides outpatient and inpatient services in different medical specialties and subspecialties. The hospital provides services (pay-for-service) and operates on a cost-containment basis. The remuneration is in the form of salaries and incentives (as a percent of the revenue). The Karmouz hospital (400 beds, 238 registered nurses) is affiliated to the HIO and is considered the main hospital for government-insured employees in Alexandria. HIO is a public institutional, government-owned entity under the Egyptian Minister of Health and Population. As such, the final decision on major policy or structural and managerial changes rests with the MOHP. As a government-owned entity, the HIO is also governed by governmental decrees and laws. It functions as a payer and provider of health care. HIO provides comprehensive curative and preventive benefits to its beneficiaries through the hospitals and clinics it owns and the health care providers it employs.

\section{Study design and sample}

The two hospitals were selected after preparing a list of all available hospitals into hospitals affiliated with the MOHP and those affiliated with the HIO. A convenient sample of nurses was selected to assess the level of nurse stress at the two randomly selected hospitals to determine the differences in stress perceptions within both organizations.

\section{Target population}

All nurses present at the time of the study were approached to be included in the study. The total number of eligible questionnaires for statistical analysis accounted for 120 forms for Shark Al Madina hospital representing 94\% and 170 forms for Karmouz hospital representing $71 \%$ of the sample under study. 


\section{Data collection method}

Data collection took place from the first week of October till the end of November 2008. The nurse stress questionnaire used in the study was previously developed and tested for validity and reliability to measure stress in clinical nursing practice. Validity was verified through face validity, content validity, and principal component analysis (PCA) using the varimax rotation for the statements included in the questionnaire. The PCA explained $56.4 \%$ of the variance and concluded with three main components under which the statements would be categorized. Dimensions were given suitable headings as follows: work aspects, working conditions, and workload. Internal consistency for the scale was calculated revealing Cronbach's alpha coefficient $r=0.88$, and Spearman-Brown coefficient for unequal length $r=0.79$. The total number of dimensions organized on the scale were $15 .^{10}$

The instrument consisted of two parts:

- Demographic data included: age, gender, marital status, number of children, educational degree, years of experience, and working department, monthly income.

- Occupational stress scale used a three-point Likert scale where low stress $=1$, moderate stress $=2$, and extreme stress $=3$. The total number of statements included in the scale was 15; whereas, the total mean score was calculated by summating all statements for every nurse then dividing the total by 15 . Cut-off points of the scale were as follows: low stress, 1 to $<1.99$; moderate stress, 2 to $<2.99$; high stress, 3 .

The statements in the instrument were: workload, work underload, fluctuation in workload, unrealistically high expectation by others of my role, coping with new situations, uncertainty about degree of responsibility, security of employment, exposure to death in working condition, coping with technology, staff shortage, poor physical conditions, lack of privacy, shortage of essential resources, poor quality of supporting staff, and difficult patients.

The nurse's total stress score (continuous variable) was calculated by adding the scores for all stress dimensions on the scale then dividing the result by 15 to obtain a score within the range of the utilized scale in the study.

Tolerance results between the stress dimensions were $\mathrm{T}<0.1$. To guard against multicollinearity within the regression model, the following variables were excluded from the stepwise multiple regression run (change work load, new situation, and shortage of staff). Each stress dimension was calculated for the mean and standard deviation. Dimension scores were added into a variable named (total stress score). The score was further divided by 15 to compute the mean stress score for the sample under study. The mean stress score ranged from 1 for mild stress to 3 for high stress. The calculated means were represented and discussed accordingly.

\section{Data analysis}

Data entry and processing were performed using SPSS software (version 15.0; SPSS Inc., Chicago, IL). Results were illustrated using descriptive tables, with the relevant tests of significance. The $5 \%$ level of significance was used throughout the statistical analysis for all relevant tests.

\section{Ethical considerations}

- The authors followed the ethical steps in securing the official acceptance for undergoing the study from the top management at both hospitals.

- The top management had no objection on mentioning the names of the hospitals as the study results do not breach any classified information related to either hospital.

- The study explores the personal level of stress among nurses working at both organizations and accordingly the results pose no implications on the way or approach of managing both hospitals.

- The identity of individuals from whom information was obtained in the course of the study was kept strictly confidential. No information revealing the identity of any individual was included in the final report or in other communication prepared throughout the course of the study.

- All nurses who participated in the study were those who actually agreed to complete the study.

- Nurses were approached with a full description of the study and its aim, after which the nurses were free to participate in the study or abstain.

\section{Results}

The mean age at Shark Al Madina hospital was 33.9 \pm 11.3 years whereas the mean age at Karmouz hospital was $33.0 \pm 10.6$ years. Table 1 shows the demographic characteristics of the sample under study. The highest percentages of nurses at Shark Al Madina and Karmouz hospitals were in the age group less than 30 years and accounted for $48.3 \%$ and $47.6 \%$ respectively, while the lowest percentages were among the age group 50+ years and accounted for $10.0 \%$ and $11.2 \%$, respectively. More than half of the sample in both hospitals were married at 59.2\% and $71.2 \%$, respectively. Most of the nurses in both hospitals 
Table I Demographic characteristics of the sample under study

\begin{tabular}{|c|c|c|c|c|c|}
\hline \multirow[t]{2}{*}{ Characteristic } & \multicolumn{2}{|c|}{ Shark AI Madina (I20) } & \multicolumn{2}{|c|}{ Karmouz (I70) } & \multirow[t]{2}{*}{$\mathbf{X}^{2}$} \\
\hline & No. & $\%$ & No. & $\%$ & \\
\hline \multicolumn{6}{|l|}{ Age } \\
\hline Less than 30 years & 58 & 48.3 & 81 & 47.6 & \multirow[t]{4}{*}{0.46} \\
\hline $30-40$ & 32 & 26.7 & 41 & 24.1 & \\
\hline $40-50$ & 18 & 15.0 & 29 & 17.1 & \\
\hline $50+$ & 12 & 10.0 & 19 & 11.2 & \\
\hline \multicolumn{6}{|l|}{ Marital status } \\
\hline Married & 71 & 59.2 & 121 & 71.2 & \multirow[t]{2}{*}{$4.53 *$} \\
\hline Not married & 49 & 40.8 & 49 & 28.8 & \\
\hline \multicolumn{6}{|l|}{ Educational level } \\
\hline Baccalaureate & 28 & 23.3 & 2 & 1.2 & \multirow[t]{2}{*}{$37.37^{*}$} \\
\hline Diploma & 92 & 76.7 & 168 & 98.8 & \\
\hline \multicolumn{6}{|l|}{ Income } \\
\hline Enough & 39 & 32.5 & 42 & 24.7 & \multirow[t]{2}{*}{2.12} \\
\hline Not enough & 81 & 67.5 & 128 & 75.3 & \\
\hline \multicolumn{6}{|l|}{ Years of experience } \\
\hline Less than 10 years & 47 & 39.2 & 69 & 40.5 & \multirow[t]{4}{*}{5.74} \\
\hline $10-20$ & 52 & 43.3 & 54 & 31.8 & \\
\hline $20-30$ & 16 & 13.3 & 37 & 21.8 & \\
\hline $30+$ & 5 & 4.2 & 10 & 5.9 & \\
\hline \multicolumn{6}{|l|}{ Department } \\
\hline Renal dialysis & 5 & 4.2 & 6 & 3.5 & \\
\hline Outpatient & 49 & 40.9 & 35 & 20.6 & \\
\hline Operating theatre & 22 & 18.3 & 29 & 17.1 & \\
\hline Inpatient surgery & 10 & 8.3 & 49 & 28.8 & \\
\hline Inpatient medicine & 18 & 15.0 & 36 & 21.2 & \\
\hline Casualty & 10 & 8.3 & 6 & 3.5 & \\
\hline Intensive care & 6 & 5.0 & 9 & 5.3 & \\
\hline
\end{tabular}

Note: ${ }^{*} \mathrm{p}<0.05$.

were holders of a diploma in nursing with $76.7 \%$ at Shark Al Madina hospital and $98.8 \%$ at Karmouz hospital. The monthly income was not enough as stated by $67.5 \%$ of nurses at Shark Al Madina hospital and $75.3 \%$ at Karmouz hospital. The highest percentage of nurses at Shark Al Madina hospital had less than 20 years of experience in nursing and accounted for $43.3 \%$ of nurses, while the highest percentage of nurses at Karmouz hospital had less than 10 years of experience and accounted for $40.5 \%$ of nurses. The highest department represented at Shark Al Madina hospital was the outpatient department which accounted for $40.8 \%$ of nurses while the highest department represented at Karmouz hospital was inpatient surgery which accounted for $28.8 \%$ of the study sample at the hospital. Nurses working at the renal dialysis unit were the least represented in both hospitals with $4.2 \%$ at Shark Al Madina hospital and 3.5\% at Karmouz hospital. Chi-square analysis revealed no significant difference between nurses at the two hospitals except for the marital status $\left(\chi^{2}=4.53\right)$ and educational level $\left(\chi^{2}=37.37\right)$.

Table 2 shows the mean stress dimension score for the dimensions on the stress scale. The highest mean stress scores were the same for both hospitals, the dimension of coping with new situations $(2.7 \pm 0.6)$ at Shark Al Madina hospital and (2.5 \pm 0.7$)$ at Karmouz hospital, and the dimension of job security $(2.7 \pm 0.6)$ at Shark Al Madina hospital and $(2.5 \pm 0.7)$ at Karmouz hospital. The lowest mean stress scores was work underload for both hospitals, with $1.6 \pm 0.7$ for Shark Al Madina and 1.6 \pm 0.7 for Karmouz hospital. There was a significant difference between the mean nurse stress scores in both hospitals as regards the dimensions of workload $(\mathrm{t}=-2.11, \mathrm{p}<0.05)$, change in workload $(\mathrm{t}=-2.11, \mathrm{p}<0.05)$, and unrealistically high expectations 
Table 2 Mean stress dimension score

\begin{tabular}{|c|c|c|c|c|c|}
\hline \multirow[b]{2}{*}{ Stress dimension } & \multicolumn{2}{|c|}{ Shark AI Madina (I 20) } & \multicolumn{2}{|c|}{ Karmouz (I70) } & \multirow[t]{2}{*}{ Test of significance } \\
\hline & Mean & SD & Mean & SD & \\
\hline Workload & 2.1 & 0.9 & 2.3 & 0.8 & $-2.11 *$ \\
\hline Work underload & 1.6 & 0.7 & 1.6 & 0.7 & 0.73 \\
\hline Change in workload & 2.4 & 0.9 & 2.3 & 0.8 & $-2.11 *$ \\
\hline $\begin{array}{l}\text { Unrealistically high expectations } \\
\text { by others of my role }\end{array}$ & 2.5 & 0.8 & 2.0 & 0.7 & $-2.03 *$ \\
\hline Coping with new situation & 2.7 & 0.6 & 2.5 & 0.7 & 1.69 \\
\hline $\begin{array}{l}\text { Uncertainty about degree of } \\
\text { responsibility }\end{array}$ & 2.4 & 0.7 & 2.4 & 0.8 & 0.42 \\
\hline Security of employment & 2.7 & 0.6 & 2.5 & 0.7 & 1.78 \\
\hline Exposure to death & 2.0 & 0.8 & 2.2 & 0.7 & -1.65 \\
\hline New technology & 2.4 & 0.7 & 2.4 & 0.8 & -0.23 \\
\hline Shortage of staff & 1.8 & 0.7 & 2.0 & 0.9 & -1.38 \\
\hline Working conditions & 2.1 & 0.8 & 2.1 & 0.9 & -0.15 \\
\hline Privacy & 2.2 & 0.7 & 2.2 & 0.8 & 0.69 \\
\hline Shortage of resources & 1.7 & 0.8 & 2.0 & 0.9 & -1.38 \\
\hline Shortage of support staff & 1.9 & 0.8 & 2.0 & 0.9 & -0.95 \\
\hline Difficult patients & 2.5 & 0.7 & 2.4 & 0.8 & 0.75 \\
\hline
\end{tabular}

Note: ${ }^{*} \mathrm{p}<0.05$

by others of my role $(t=-2.03, p<0.05)$. The mean stress score for two of the significant dimensions were higher at Shark Al Madina hospital: change in workload (mean $=2.4$, $\mathrm{SD}=0.9$ ) and unrealistically high expectations by others of my role (mean $=2.5, \mathrm{SD}=0.8$ ), while the mean stress score for nurses at Karmouz hospital was higher as regards the dimension workload (mean $=2.3, \mathrm{SD}=0.8$ ).

Table 3 shows the results of the stepwise multiple regression for the stress dimensions included in the scale that explain the variance in the nurse's total stress score (dependent variable). The Shark Al Madina hospital model results were: workload $(\beta=1.38)$, security $(\beta=5.04)$, and shortage of support staff $(\beta=3.39)$. The significant dimensions explain $77 \%$ of the variance $\left(R^{2}=0.77, p<0.05\right)$. The Karmouz hospital model results were security $(\beta=4.78)$ and shortage of resources $(\beta=3.66)$. The significant dimensions explain $76 \%$ of the variance $\left(R^{2}=0.76, p<0.05\right)$.

\section{Discussion}

Nurses and nurse supervisors play a pivotal role in creating healthy working environments that engage and retain nurses in the workforce. The ability to sustain healthy work environments for practice assumes that the nurse has adequate resources available to handle complexities of the work environment and meet the demands of an increasingly responsible role. Both hospitals shared the highest stress means for factors of coping with new situations, security employment, and difficult patients. This could be explained in light of the fact that Shark Al Madina hospital is a tertiary level facility specializing in complex open-heart surgeries and post-operative complications. Similarly, Karmouz hospital serves the laborers and craftsmen working at all the factories and companies in Alexandria, thus nurses may face during their shifts a wide variety and array of cases and complications. Nurses scored high mean stress scores for employment security in both hospitals. It is evident that the global financial crisis that was taking place at the time of data collection could have had an impact on the responses of the nurses who had participated in the study. Nurses at Shark Al Madina hospital had a higher mean stress score for employment security than nurses at Karmouz hospital owing to the fact that a number of nurses are working on a contractual basis and an incentive system based on work volume outcome, and the hospital is operating according to cost-containment financial schemes. It could be concluded that such factors would pose strenuous pressure on nurses, as eventually the results obtained proved. The two hospitals under study are currently passing through a reform process. The Shark Al Madina hospital is on the way to privatization while the HIO anticipates the approval of a new Health Insur- 
Table 3 Stepwise multiple regression results

\begin{tabular}{llll}
\hline Variable & Beta $(\beta)$ & Standard error & P value \\
\hline Shark Al Madina hospital & & & \\
Workload & 1.38 & 0.21 & 0.0001 \\
Security & 5.04 & 0.33 & 0.0001 \\
Shortage of support staff & 3.39 & 0.23 & 0.0001 \\
$\quad$ Constant & 9.51 & 1.19 & \\
Karmouz hospital & & & 0.0001 \\
Security & 4.78 & 0.26 & 0.0001 \\
Shortage of resources & 3.66 & 0.21 & \\
Constant & 13.89 & 0.87 & \\
\hline
\end{tabular}

Notes: $R^{2}$ Shark Al Madina Hospital $=0.77, F=133.3, p<0.05 ; R^{2}$ Karmouz Hospital $=0.76, F=276.8, p<0.05$.

ance Act to be endorsed by the Egyptian Parliament. Such periods of change are characterized by turbulence regarding human behavior especially in health care organizations as well as reluctant decision-making on behalf of top management until matters are clarified and this reflects on the assessment of human and nonhuman resources. Mean stress scores were higher for Shark Al Madina hospital in two of the highest three significant dimensions: change in workload and unrealistically high expectations by others of my role. Workload was the third significant dimension between the two hospitals; the mean stress score was higher at Karmouz hospital. Such a finding would be related to the fact that nurses at Karmouz hospital might deal with patients of low educational levels and economic standards with all the repercussions of the former factors on the personal behavior of such patients and their relatives when dealing with nurses, in addition to the administrative and legislative factors previously mentioned. Stepwise multiple regression analyses revealed that workload, shortage of support staff, and shortage of resources appear to be major causes of stress facing the nursing profession which were the significant factors of nurse stress in a recent study. ${ }^{11}$ Another study identified nurse job stressors as poor staffing, mandatory overtime for high census, and lack of materials to complete required tasks. ${ }^{12}$ It is obvious that providers and consumers of health services always have high expectations from nurses owing to the fact that nurses constitute the backbone for health care facilities due to their prolonged and close contact with both parties. Two studies in China confirmed the relationship between job stress in nurses to job satisfaction and the intention to stay and between the stability of the health care workforce and quality of care provided. ${ }^{13,14}$ It is important for health administrators to view the importance of occupational nurse stress and its implications for health care. Also it is crucial to provide continued administrative support, appropriate training programmes to deal with potentially stressful conditions in the health facility, and a work environment that fosters open communication with the top management. ${ }^{15}$

\section{Study limitations}

Participants were not recruited in the study using probabilitysampling strategies, which limits the generalization of the study. Differences across hospitals in other organizations (eg, Curative Organization, Army, and University of Alexandria hospitals) as regards the level of stress need to be further explored. Response bias may have been present in the form of over-reporting or under-reporting of stress.

\section{Conclusion}

Stressors among nurses appear to be the same despite differences in the organizational or hierarchical structure they work in, or the type of consumer they serve. It is important to reduce occupational stress in nurses and to strengthen their coping resources to prevent nurse burnout. This could be achieved with job redesign, modification of shift work systems, and working hours. Offering occupational health education could play a role in improving stress management, as well as job security assurances especially during the global financial crisis.

\section{Disclosure}

The authors report no conflicts of interest in this work.

\section{References}

1. Judkins SK. Stress among nurse managers: can anything help? Nurse Res. 2004;12(2):58-70.

2. Tzeng H. The influence of nurses' working motivation and job satisfaction on intention to quit: an empirical investigation in Taiwan. Int J Nurs Stud. 2002;39:867-878.

3. Greenglass ER, Burke RJ. Hospital restructuring and burnout. J Health Hum Serv Adm. 2002;25(1):89-114.

4. Nedd N. Perception of empowerment and intent to stay. Nurs Econ. 2006;24(1):13-18.

5. Powell S. Job stress versus success factors for case management. Nurs Case Manag. 1996;1(3):125-132.

6. Shirey MR. Authentic leaders creating healthy work environments for nursing practice. Am J Crit Care. 2006;15(3):256-267.

7. Erenstein CF, McCaffrey R. How healthcare work environments influence nurse retention. Holist Nurs Pract. 2007;21(6):303-307.

8. Kreitzer MJ, Wright D, Hamlin C, Towey S, Marko M, Disch J. Creating a healthy work environment in the midst of organizational change and transition. J Nurs Adm. 1997;27(6):35-41.

9. McCauley KM. A message from the American Association of Critical-Care Nurses. Am J Crit Care. 2005;14:186.

10. Zaghloul AA. Developing a tool to assess nurse stress. J Egypt Public Health Assoc. 2008;83(3,4):223-237.

11. Shirey MR, Ebright PR, McDaniel AM. Sleepless in America. Nurse managers cope with stress and complexity. J Nurs Admin. 2008;38(3):125-131. 
12. Braithwaite M. Nurse burnout and stress in the NICU. Adv Neonatal Care. 2008;8(6):343-347.

13. Wu S, Zhu W, Wang Z, Wang M, Lan Y. Relationship between burnout and occupational stress among nurses in China. $J$ Adv Nurs. 2007;59(3):233-239.
14. Chen YM, Chen SH, Tsai CY, Lo LY. Role stress and job satisfaction for nurse specialists. $J$ Adv Nurs. 2007;59(5):497-509.

15. Almost J, Laschinger HKS. Workplace empowerment, collaborative work relationships, and job strain in nurse practitioners. $J$ Am Acad Nurse Pract. 2002;14(9):408-420. 
